\title{
State of Health and Charge Estimation Based on Adaptive Boosting integrated with particle swarm optimization/support vector machine (AdaBoost-PSO-SVM) Model for Lithium-ion Batteries
}

\author{
Ran $\mathrm{Li}^{1}$, Wenrui $\mathrm{Li}^{2, *}$, Haonian Zhang ${ }^{2}$ \\ ${ }^{1}$ Engineering Research Center, Ministry of Education of Automotive Electronics Drive Control and \\ System Integration, Harbin University of Science \& Technology, Harbin, China \\ ${ }^{2}$ School of Electrical and Electronic Engineering, Harbin University of Science \& Technology, \\ Harbin, China \\ *E-mail: dapangjing@163.com
}

Received: 3 October 2021 / Accepted: 20 November 2021 / Published: 5 January 2022

\begin{abstract}
The state of charge (SOC) and state of health $(\mathrm{SOH})$ of a power battery system are the research hotspots of researchers in recent years. An accurate state estimation is conducive to research on battery life optimization and guarantees the safe driving of electric vehicles. The use of artificial intelligence, machine learning and other methods has always been the mainstream of research on SOC and SOH prediction, but there are defects such as a strong data dependence, a large calculation volume and a longtime consumption. in view of this, a battery SOC-SOH online estimation method is proposed in the previous work of this paper based on PSO-SVM algorithm to solve the above problems. However, due to the PSO-SVM algorithm, there is a problem that the stability of the estimated battery SOH is not high. Therefore, an integrated learning AdaBoost algorithm is introduced in this paper to improve the PSOSVM regression model, meanwhile through integrated processing, multiple weak learners are combined to construct a strong regression. Simulation and experimental analysis show that this method has a good data adaptability and accuracy, whose average estimation error does not exceed 2.316.
\end{abstract}

Keywords: Lithium battery, SOH, AdaBoost, SVM, BMS

\section{$\underline{\text { FULL TEXT }}$}

(C) 2022 The Authors. Published by ESG (www.electrochemsci.org). This article is an open access article distributed under the terms and conditions of the Creative Commons Attribution license (http://creativecommons.org/licenses/by/4.0/). 